\title{
Reliability of the Q Force; a mobile instrument for measuring isometric quadriceps muscle strength
}

\author{
K. W. Douma ${ }^{1,2^{*}}$, G. R. H. Regterschot ${ }^{3}$, W.P. Krijnen ${ }^{1}$, G. E. C. Slager ${ }^{4}$, C. P. van der Schans ${ }^{1,2}$ and W. Zijlstra ${ }^{5}$
}

\begin{abstract}
Background: The ability to generate muscle strength is a pre-requisite for all human movement. Decreased quadriceps muscle strength is frequently observed in older adults and is associated with a decreased performance and activity limitations. To quantify the quadriceps muscle strength and to monitor changes over time, instruments and procedures with a sufficient reliability are needed. The Q Force is an innovative mobile muscle strength measurement instrument suitable to measure in various degrees of extension. Measurements between 110 and $130^{\circ}$ extension present the highest values and the most significant increase after training.

The objective of this study is to determine the test-retest reliability of muscle strength measurements by the $Q$ Force in older adults in $110^{\circ}$ extension.

Methods: Forty-one healthy older adults, 13 males and 28 females were included in the study. Mean (SD) age was 81.9 (4.89) years. Isometric muscle strength of the Quadriceps muscle was assessed with the Q Force at $110^{\circ}$ of knee extension. Participants were measured at two sessions with a three to eight day interval between sessions. To determine relative reliability, the intraclass correlation coefficient (ICC) was calculated. To determine absolute reliability, Bland and Altman Limits of Agreement (LOA) were calculated and t-tests were performed.

Results: Relative reliability of the Q Force is good to excellent as all ICC coefficients are higher than 0.75 . Generally a large $95 \%$ LOA, reflecting only moderate absolute reliability, is found as exemplified for the peak torque left leg of $-18.6 \mathrm{~N}$ to $33.8 \mathrm{~N}$ and the right leg of $-9.2 \mathrm{~N}$ to $26.4 \mathrm{~N}$ was between 15.7 and 23.6 Newton representing $25.2 \%$ to $39.9 \%$ of the size of the mean. Small systematic differences in mean were found between measurement session 1 and 2.

Conclusion: The present study shows that the Q Force has excellent relative test-retest reliability, but limited absolute test-retest reliability. Since the Q Force is relatively cheap and mobile it is suitable for application in various clinical settings, however, its capability to detect changes in muscle force over time is limited but comparable to existing instruments.
\end{abstract}

Keywords: Quadriceps, Isometric muscle strength, Q force, Elderly

\footnotetext{
* Correspondence: k.w.douma@pl.hanze.nl

${ }^{1}$ Research and Innovation Group in Healthy Aging, Allied Health Care and Nursing, Hanze University of Applied Sciences Groningen, Groningen, The Netherlands

2Department of Rehabilitation Medicine, University of Groningen, University

Medical Center Groningen, Groningen, The Netherlands

Full list of author information is available at the end of the article
} 


\section{Background}

Muscle strength is essential for all physical activities such as activities of daily living, work, sports and maintaining posture [1-4]. Reduced muscle strength is frequently apparent in older participants and creates a potential risk for a decline of activities. It may induce balance deficits, a risk of falling [3-10], and predisposition for disability, premature nursing home admission, and ultimately premature mortality $[5,11]$. Also functional walking tests and rising tests, such as the timed up and go test, are used to predict the occurrence of future falls. Retrospective studies show that these tests are associated to a history of falls, the predictive capability however is limited [8, 11-13].

The quadriceps muscle is prominently important due to its major contribution to activities such as walking stairs, rising from a chair, and walking [3, 4, 7].

To quantify Quadriceps muscle strength and to monitor changes over a period of time, a muscle strength measurement with high reliability is required. Several viable quantitative muscle strength measurement methods are available. The Medical Research Counsel Scale (MRC) is the most commonly and clinically used method. The MRC scale ranges over 6 grades, 0 to 5 . Unfortunately, this scale is inaccurate and inefficient in detecting changes over a period of time [14-18]. MRC grade 4 covers a wide range from 4 up to $99 \%$ of the generated strength [19]. More precise measurements are possible with handheld dynamometry allowing muscle strength to be measured on a continuous scale. Handheld dynamometry has been demonstrated to have good reliability according to the intra class correlation coefficient of 0.8 or higher [19-22]. Measurements with a handheld dynamometer, however, are required to be performed in a reproducible joint position of $90^{\circ}$ flexion [23-25]. Joint positions other than $90^{\circ}$ flexion however, have exhibited greater maximal muscle strength values [26-28], as well as more extensive sensitivity when detecting changes over time [27]. For the knee the highest values were recorded by measurements at 110 and $130^{\circ}$ extension and the most significant increase after training was determined in a knee angle position between 110 and $130^{\circ}$ extension [28]. Another possible limitation of handheld dynamometry is the variance induced by different observers, i.e., certain patients restrain their efforts when working with presumed weaker observers. Consequently, fixation during measurement in healthy participants might be difficult [22, 23, 29]. The fixation possibilities of the observers are limited when using handheld dynamometry and this may negatively influence reliability and validity of muscle strength measurements [22, 23, 30]. An additional relevant aspect in any non-computerized type of muscle strength measurement is that it does not provide insight into coordination, slope, or duration of the contraction.
Sustainable and repetitive contractions, however, are required in sports, and activities of daily living.

Another type of muscle strength measurement is isokinetic muscle strength measurement. Isokinetic equipment is capable of measuring from different body positions and angles, presenting an abundance of graphical, numerical, and derivative information which are considered to be the gold standard. The equipment, however, is expensive and immobile, and the procedure is time consuming.

The $Q$ Force chair has been recently developed as a successor of the Quadriso Tester [31] to measure isometric muscle strength of the Quadriceps muscle in different joint angles. Advantages of the Q Force compared to other instrumentation is that it is transportable and can be employed easily in a clinical setting as for example a hand held dynamometer. It provides however as isokinetic instrumentation, relevant graphical, numerical and derivative information about the contraction besides measured peak values.

However, the test-retest reliability of the $\mathrm{Q}$ Force in older adults is unclear. Therefore the purpose of this study was to determine the test retest reliability of muscle strength measurements with the $\mathrm{Q}$ Force in older adults.

\section{Methods}

The Medical Ethics Committee of the University Hospital Groningen approved this study.

All participants gave written informed consent before data collection began.

\section{Participants}

In this study, inclusion criteria were:

*At least 70 years of age, being able to walk $\geq 10 \mathrm{~m}$ without support, and rise from a chair without resources or assistance;

*Absence of cardiovascular/respiratory or neurological disorders;

"No comorbidity or cognitive disorders that influence mobility, understanding, or execution of measurements. No current or recent participation in exercise programs or any other physical intervention;

*No orthopedic surgery or stroke within the last six months;

Participants were included after providing and signing informed consent. The Medical Ethics Committee of the University Medical Center Groningen, The Netherlands, approved the study protocol.

\section{Design}

Muscle strength was assessed on two occasions within three to eight days. Four trials were performed on each occasion at approximately the same time of the day. If the participant was unable to perform four trials for any 
reason, fewer repetitions were performed and used for analysis

\section{Device}

The Q Force (Fig. 1) has been constructed for measuring isometric Quadriceps muscle strength. It consists of a chair with an attached, adjustable fixed leg brace at the front (Fig. 2). Three sensors are located in the brace to determine the generated force (Newton); the angle between the horizontal chair surface and the brace and the distance between the force transducer and the rotation axle of the brace (millimeter). All three signals pass through an analog-digital converter, are read and saved on a laptop.

The chair incorporates a solid frame, base, back support, and a seat. Bars are fitted at both sides of the seat for manual fixation. The height of the sitting surface is fully adjustable. At the left and right bottom of the seat, in an anterior posterior direction, rails are attached to which the brace is connected so that both the left and right leg can be tested. The fixed brace consists of a

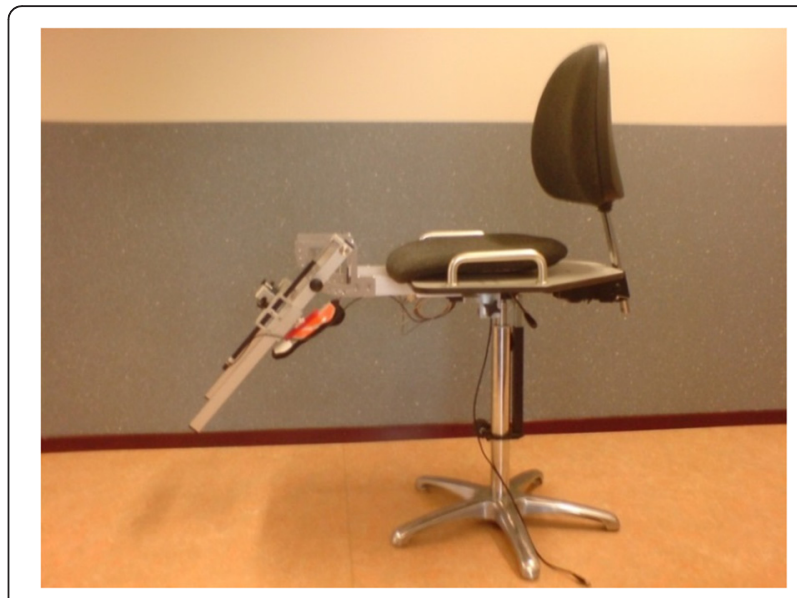

Fig. 2 Q Force with fixed brace at the front

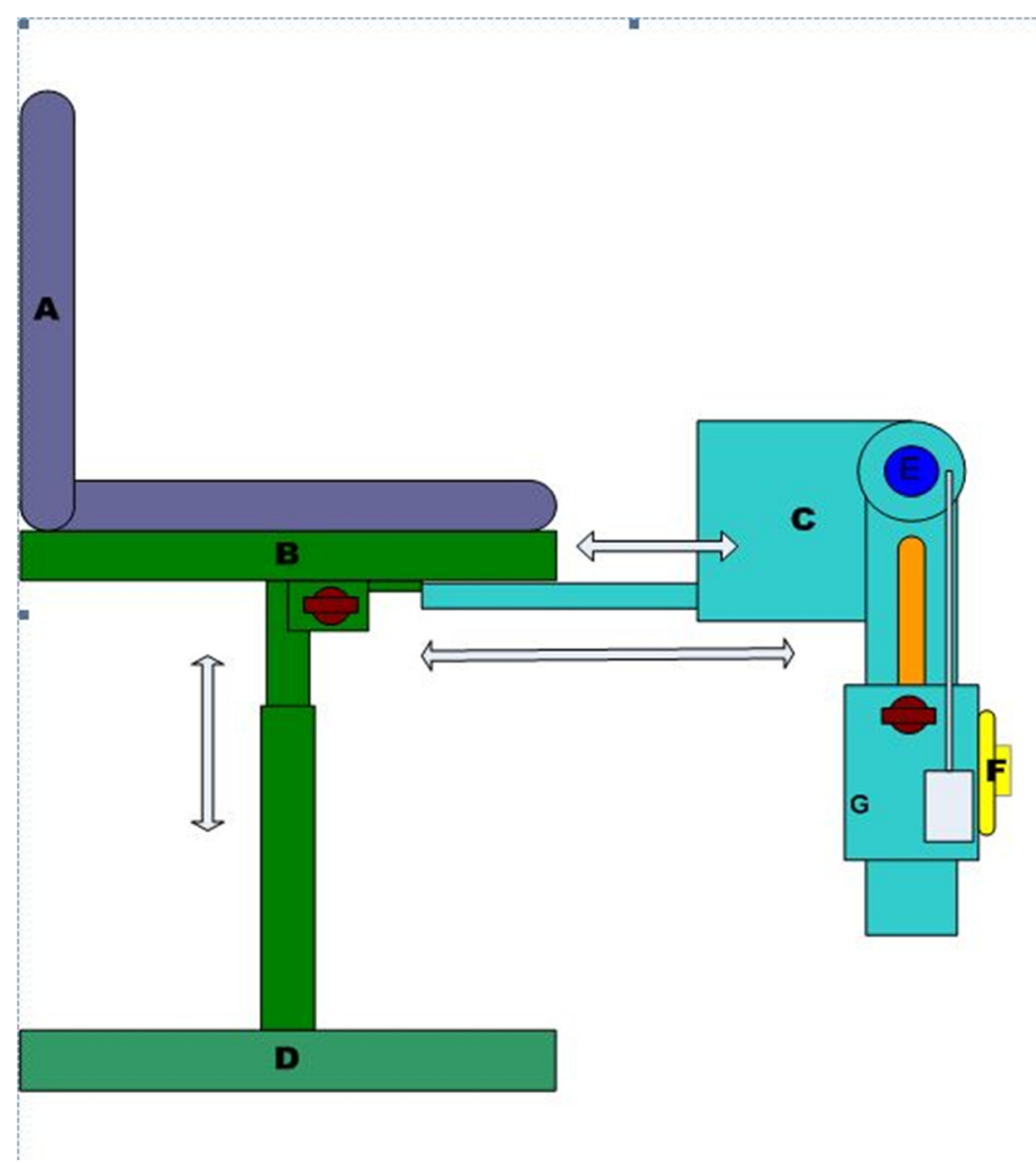

Fig. 1 Schematic view, Q Force. $\mathbf{a}=$ Back support, $\mathbf{b}=$ Seat, $\mathbf{c}=$ Fixed brace, $\mathbf{d}=$ Base, $\mathbf{e}=$ Astrolabe/Goniometer, $\mathbf{f}=$ Force transducer, $\mathbf{g}=$ Distance transducer 
fixed horizontal and an adjustable distal component with a hinge in between; the brace can be slid horizontally via rails. The brace is adjustable to fit the subject's upper leg dimensions. This affords placing the rotation axle of the brace in the same position as the rotation axle of the knee for that specific angle (Fig. 3). The measuring angle of the fixed brace is adjustable between $90^{\circ}$ and $180^{\circ}$. The force transducer is covered with a pad to minimize pressure on the subject's lower leg. The position of the pad is adjustable in vertical and horizontal directions in accordance with the subject's dimensions.

\section{Computer and control \\ Hardware}

The hardware consists of an analog-digital converter, a force, and a distance and angle transducer. The ADC is an NI-9219 4Ch Universal Analog input module. As an interface, the NI USB-9162 converter is utilized for establishing a USB connection between the ADC and the laptop. National Instruments Corporation Austin. The force transducer is an LLB400 Loadcell which is capable of measuring force up to 1100 Newton with a break load of 1650 Newton (Futek, Irvine). The distance transducer is a CLS1321 Linear potentiometer (Active Sensors Indianapolis). The angle is measured by a single strike potentiometer.

\section{Software}

The accompanying software is developed by the ICT Software Development Laboratory of the Faculty of Medical Sciences from the University of Groningen and the University Medical Center Groningen in the Netherlands.

\section{Outcome measures}

We measured and calculated a peak value and three different average torque operationalization's for each separated measurement; Peak Torque (PT), Filtered Peak Torque (FPT), Median Peak Torque (MPT) and Average Plateau Peak Torque (APT).

$\mathrm{PT}$ is the actually measured peak value and is calculated as Fmax $* \mathrm{r}+$ fixation torque. Fmax is the registered maximal force; $r$ is the distance between the knee joint rotation point and the sensor on the lower leg; fixation torque is the torque required keeping the lower leg stabilized against gravity. Arrow 2 in Fig. 3 illustrates the PT value.

Filtered Peak Torque is the average peak torque of the sample that recorded the PT value [1] with the sample before $(-1)$ and the sample after $(+1)$ this sample and is calculated as FPT $=\left(\frac{\text { total torque }(i-1)+\text { total torque }(i)+\text { totaltorque }(i+1))}{3}\right.$.

Arrow 1 and 3 in Fig. 3 indicate FPT.

MPT is defined as the median of the total torque above the level of $0.5 *$ PT. This is calculated as: median total torque $=$ median (total torque $(\mathrm{a}: \mathrm{b})$ ) whereby $a$ is defined as the moment where total torque is greater than $0.5 * \mathrm{PT}$ for the first time, and $b$ is defined as the moment where total torque is smaller than $0.5 * \mathrm{PT}$ for the first time. Line a-b in Fig. 4 represents $50 \%$ of the PT level. Line c-d represents the MPT.

APT is the value above $50 \%$ of the PT level. It is the average peak torque over the plateau phase. It is calculated as: average (total torque (c:d)) $c$ is defined as the initial sample following sample $a$ when the absolute difference with sample c -1 is less than $4 \mathrm{Nm}$. Sample $d$ is defined as the sample following sample $a$ where the absolute difference with sample $d-1$ is smaller than 4 Newtonmeter $(\mathrm{Nm})$. Point $e$ in Fig. 4 represents the first sample where the increase of the generated force is less than $4 \mathrm{Nm}$, and point $f$ represents the last sample where the decline of the generated force $f$ is less than $4 \mathrm{Nm}$. Line $e$ - $f$ represents the calculated value. This signifies that a plateau phase between samples $c$ and $d$ can be recognized in which the absolute differences between the sequential samples during this plateau are less than $4 \mathrm{Nm}$. This was considered a reliable contraction [30] representing the maximum generated torque. The level of elevation of this plateau corresponds with the generated torque. The mass and center of gravity of the lower leg were calculated according to Winter 1979 [32]. The sample ratio which recorded the generated forces was $2 \mathrm{~Hz}$.

Fig. 3 represents a graphic interpretation of the outcome measures. The vertical axis represents the generated torque while the horizontal axis represents the time. The letters $g$ and $h$ correspond with the start and the end of the contraction, a-b represents $05 * \mathrm{PT}$ level, $\mathrm{c}-\mathrm{d}$ represents the MPT and e-f represents the APT.

\section{Data acquisition}

All algorithms for data acquisition were programmed and collected in Matlab Mathworks 7, Nathick, USA. The collected data were transferred to Microsoft Excel 2010 files for statistical analysis.

\section{Measurement procedure}

The angle of the fixed leg brace was positioned at $110^{\circ}$, and the subject was subsequently positioned in the chair without back support and with the back of their knee positioned against the seat. The lateral condyle of the femur was aligned with the rotation point of the $Q$ Force. The force transducer was positioned $3 \mathrm{~cm}$ above lateral malleolus. The tuberosity of the tibiae was aligned with the sensor to prevent adduction, abduction, or rotation in the knee or hip in the starting position. The computer program was initiated as the subject was instructed to elevate the leg to minimize pressure on the force transducer in order to calibrate the system. The distance between the 


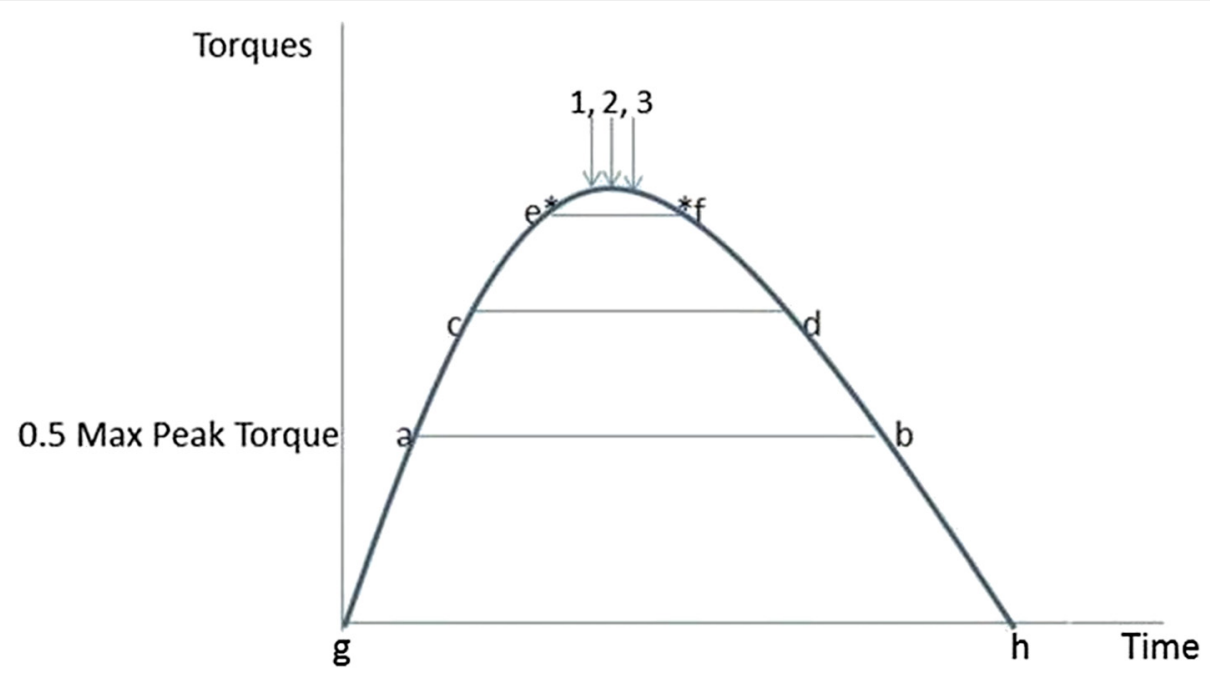

Fig. 3 Graphic representation

transducer and the rotation point was determined to calculate the generated torque and the average knee angle. Additionally, the average distance from the rotation axle to the force transducer was measured to determine whether the current angle was actually $110^{\circ}$. Following the calibration, the actual measurement began whereby the left leg was tested first. Participants were allowed to fixate themselves to the sidebars using their hands. Four trials were performed for each leg. If the subject was not capable of performing four trials for any reason, fewer repetitions were performed and applied to the analysis. A 1 min break was administered between the successive trials. Following each trial, it was evaluated if the contraction had been maximal by asking, "Was this a maximal effort?" If the contraction had not been maximal, it was excluded.

\section{Instruction of the participant}

The participants were instructed as follows: "Extend your knee as forceful as possible. I will measure the strength you will generate. You are allowed to fixate yourself to the side bars using your hands. Each leg is tested four times each with a one minute break in between. I will encourage you and tell you when to start and when to stop. The maximal contraction has to endure for three seconds. Build up your contraction gradually and let go slowly.

\section{Statistical analyses}

All data were analyzed with the statistical programming language string R version 3.1.2 2014.

To determine relative reliability, the two-way absolute agreement variant of the intraclass correlation coefficient (ICC) was calculated. To determine absolute reliability the Bland and Altman limits of agreement (LOA) were calculated according to $1.96 * \mathrm{SD}$ of the mean difference [33]. The LOA were calculated for each pair of measurements and were interpreted with regard to the clinical relevance to their size.

Bland and Altman plots were constructed with the difference and the mean of the of the two measurements for each subject. Means, standard deviation, mean difference, and standard deviations were calculated for descriptive purposes. The paired t-test was used to test for systematic differences in mean between session 1 and session2. ICCs were interpreted as: ICC $<0.25$ low; $0.25<$ ICC $<0.50$ moderate; $0.50<$ ICC $<0.75$ moderate to good; and ICC $>$ 0.75 is excellent reliability [34-36]. A level of 0.05 was considered significant.

\section{Results}

\section{Participants}

Forty-one healthy older adults were included in the study comprised of 13 males and 28 females. Mean (SD) of age was 81.9 (4.89) years; of body weight was 78.5 (13.0) $\mathrm{kg}$; and of body height $165.3(5.8) \mathrm{cm}$.

\section{Outcome measures}

Table 1 presents the reliability results of session 1 and session 2 for the left and right leg.

All differences between Session1 and Session2 are significant according to the Paired T-Test. It can be observed from Table 1 that the ICC coefficients are higher for the right than for the left leg and all ICC coefficients are greater than 0.75 . The LOA's are smaller for the right leg compared to the left and are in general relatively large, 17.6 to 26.5 Newton, and represent values between $25.2 \%$ to $39.9 \%$ of the mean measured values of session 1 and session2. The LOAs are smaller for the right than for the left leg.

Figures 4, 5, 6, 7, 8, 9, 10 and 11 present Bland and Altman plots of the limits of agreement between session1 and session 2 measurements of the mean Peak Torque; the 
Table 1 Shows the intraclass correlations, the t-test outcomes and the LOA's for the left and right leg

\begin{tabular}{|c|c|c|c|c|c|c|c|c|c|}
\hline & & \multirow{2}{*}{$\begin{array}{l}\text { Session } 1 \\
\text { Mean (SD) }\end{array}$} & \multirow{2}{*}{$\begin{array}{l}\text { Session } 2 \\
\text { Mean (SD) }\end{array}$} & \multirow{2}{*}{$\begin{array}{l}\text { diff } \\
\text { Mean (SD) }\end{array}$} & \multirow[b]{2}{*}{ t-test } & \multicolumn{3}{|c|}{$P$ value } & \multirow[b]{2}{*}{ Loa \% Mean } \\
\hline & & & & & & ICC & L. Loa & U. Loa & \\
\hline PT & left & $63.1(27.2)$ & $70.7(29.2)$ & $7.6(13.4)$ & 0.0078 & 0.89 & -18.6 & 33.8 & 39.1 \\
\hline PT & right & $66.1(30.4)$ & $74.8(34.2)$ & $8.6(9.1)$ & 0.0001 & 0.96 & -9.2 & 26.4 & 25.1 \\
\hline FPT & left & $62.5(27.0)$ & $70.2(29.1)$ & $7.7(13.5)$ & 0.0077 & 0.88 & -18.8 & 34.2 & 39.9 \\
\hline FTP & right & $65.6(30.3)$ & $74.0(34.1)$ & $8.4(9.1)$ & 0.0001 & 0.96 & -9.4 & 26.2 & 25.5 \\
\hline MPT & left & $58.5(26.0)$ & $66.4(28.5)$ & $7.9(12.5)$ & 0.0037 & 0.89 & -16.6 & 32.4 & 39.2 \\
\hline MPT & right & $62.0(29.1)$ & 69.9 (32.9) & $7.9(9.0)$ & 0.0001 & 0.96 & -9.7 & 25.5 & 26.7 \\
\hline APT & left & $58.3(26.2)$ & 65.9 (28.6) & 7.6 (12.9) & 0.0058 & 0.80 & -17.6 & 32.8 & 38.7 \\
\hline APT & right & $61.8(29.6)$ & 70.2 (33.5) & $8.4(9.1)$ & 0.0001 & 0.96 & -9.4 & 26.2 & 26.9 \\
\hline
\end{tabular}

PTL Peak Torque, FTP Filtered Peak Torque, MPT Median Peak Torque, APT Average Plateau Peak Torque, expressed in Newton, ${ }^{*}$ Significant level; $\leq 0.01$, ICC; Intraclass Correlation Coefficient, L.LOA; Lower Limits of Agreement, U. LOA upper Limits of Agreement. LOA as percentage of mean of session 1 and session 2

mean Median Peak Torque; the mean Plateau Peak Torque; and the mean Filtered Peak Torque of the left and right leg, respectively.

The uninterrupted horizontal line is located above zero in all cases due to the systematic difference between Session1 and Session2. The variation of all of the measurements is not increasing with increasing $Q$ Force torque, and there are only minimal outlying points observed. The right leg measurements result in smaller LOA than those for the left.

\section{Discussion}

The outcomes of this study indicate that muscle strength measurements with the $\mathrm{Q}$ Force at $110^{\circ}$ flexion of the knee are reliable according to the ICC coefficients. The ICC coefficients exceed 0.75 which indicate excellent relative test-retest reliability [34-36]. However, the obtained LOA's are substantial indicating moderate absolute reliability. The mean values at the second measurement are significantly higher than those at the first measurement. The encountered ICC and LOA presented are consistently better for the right leg compared to the left.

The obtained ICC coefficients indicate that the $Q$ Force is capable of reliably measuring muscle strength on group level [34-36]. The encountered ICC coefficients are between 0.80 and 0.95 and therefore consistent with coefficients determined in other muscle strength measurement reliability studies $[20-23,29,37,38,40,41]$. The

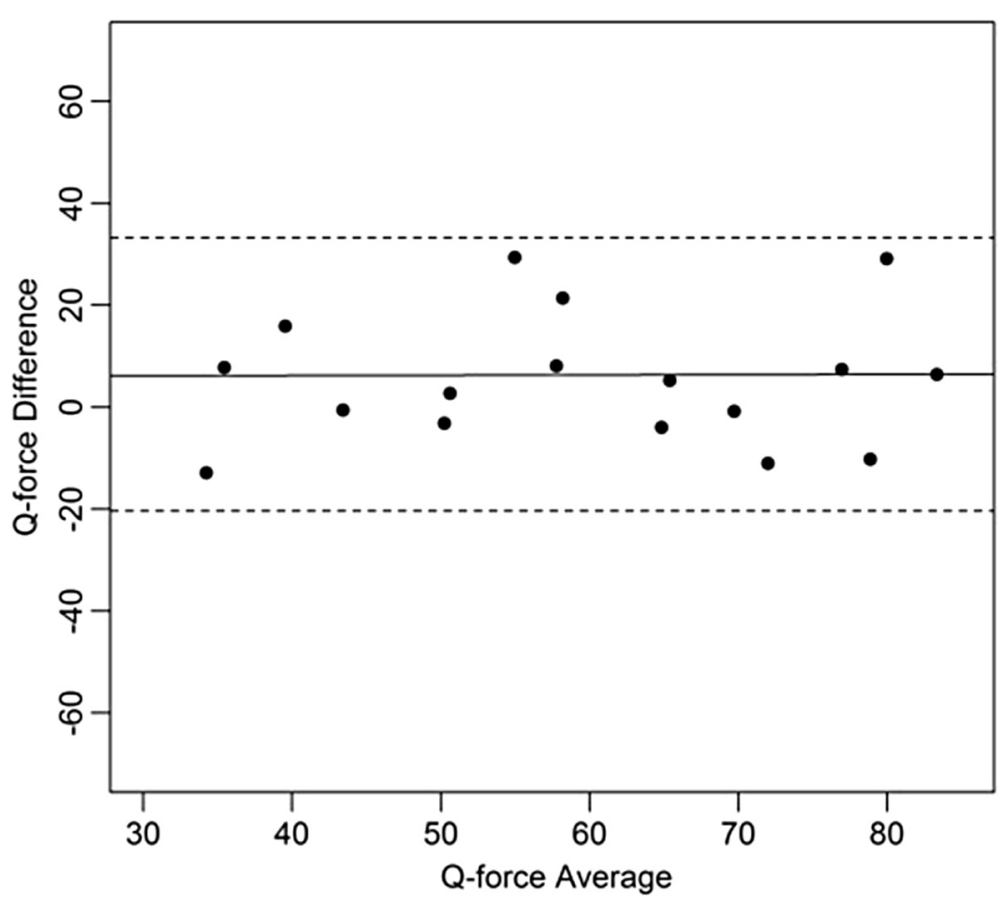

Fig. 4 Limits of Agreement for mean Peak Torque measurements-left 


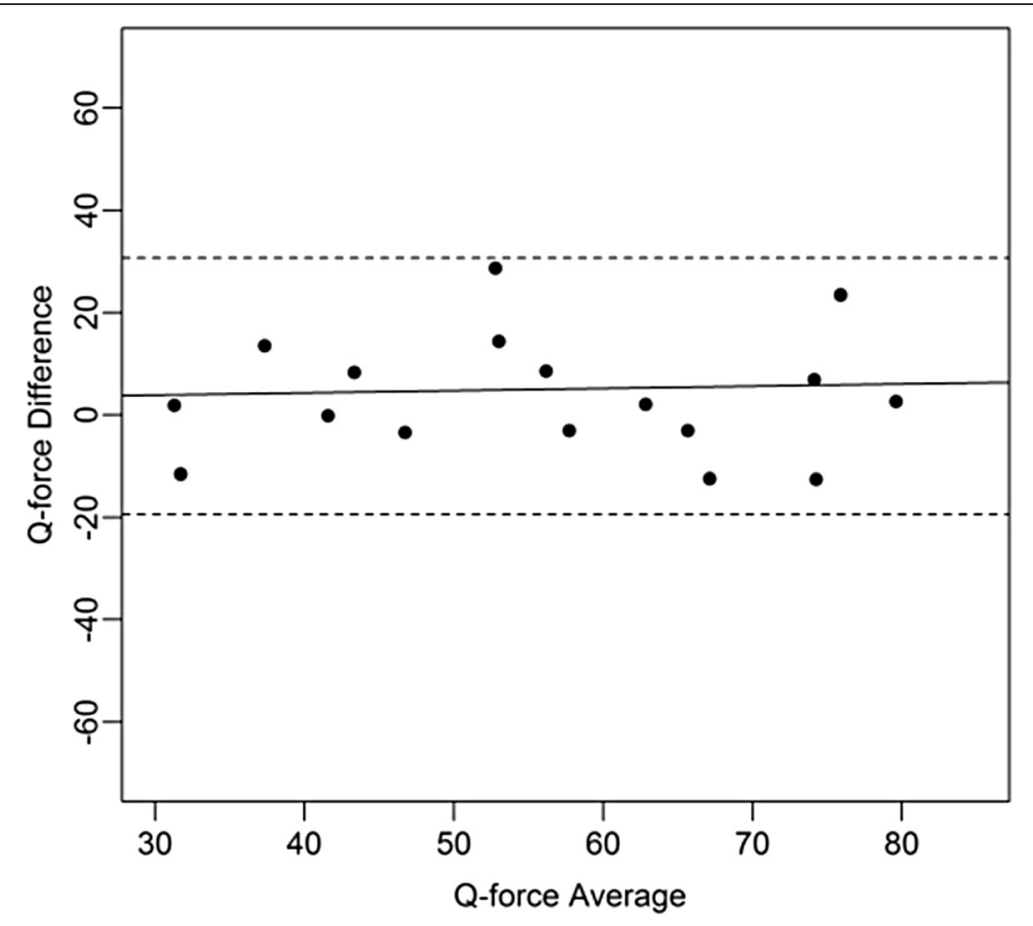

Fig. 5 Limits of Agreement for mean Median Peak Torque measurements-left

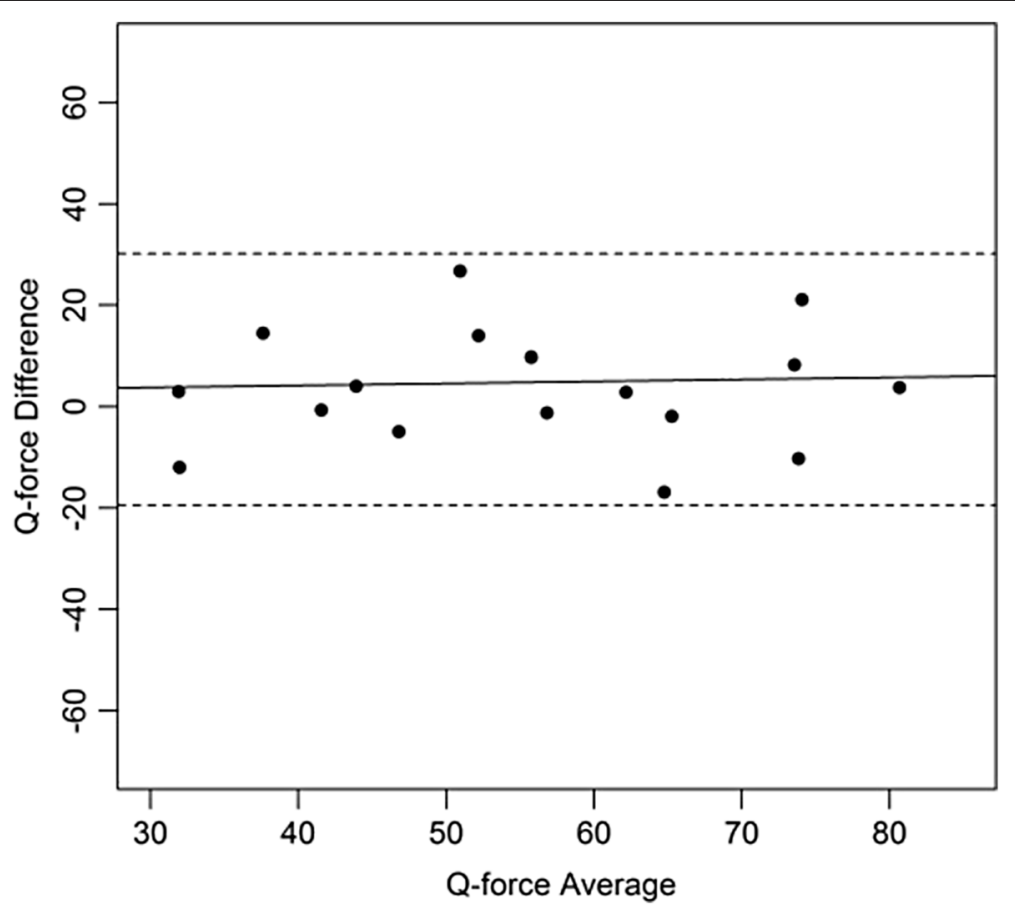

Fig. 6 Limits of Agreement for meanPlateau Peak Torque measurements-left 


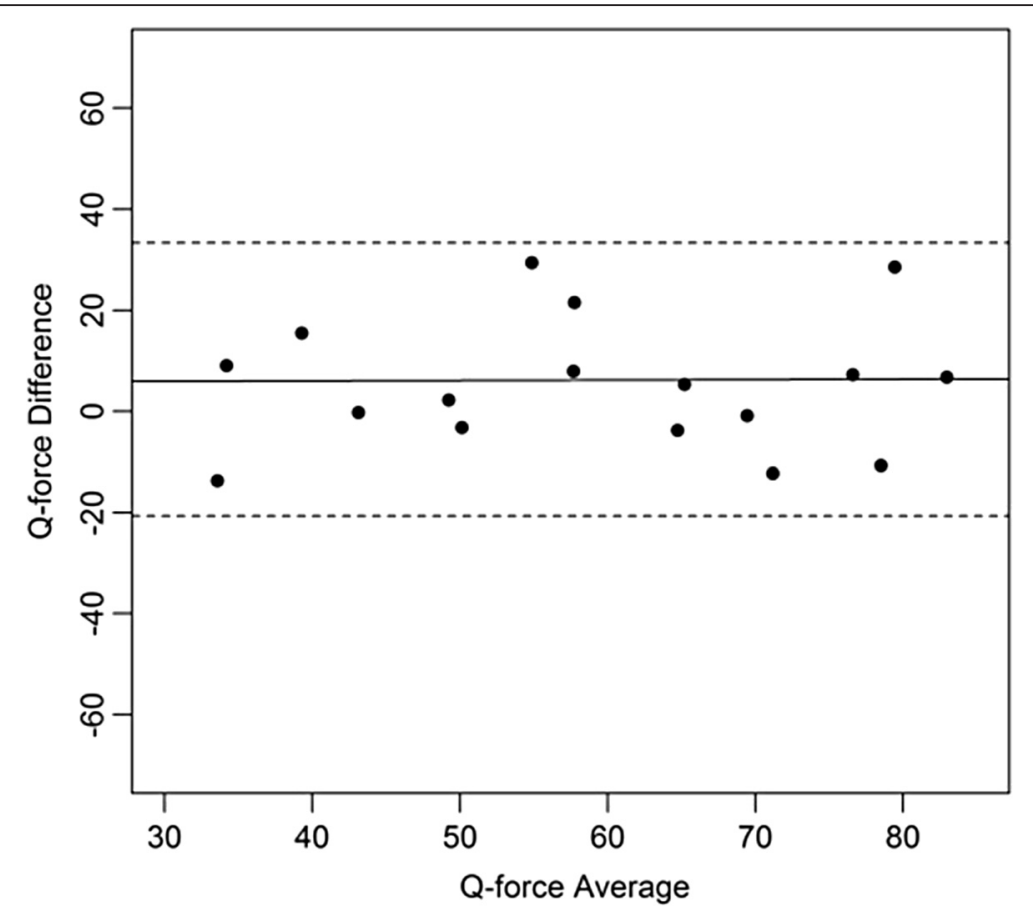

Fig. 7 Limits of Agreement for mean Filtered Peak Torque measurements-left

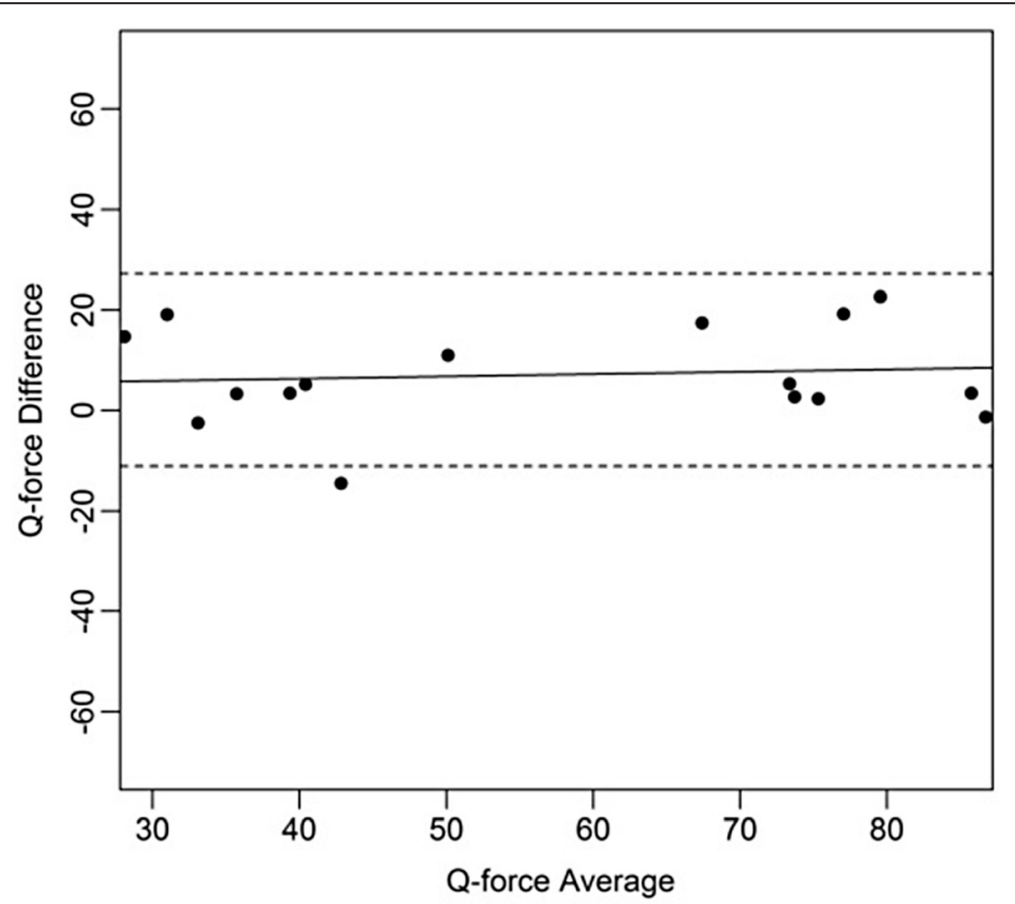

Fig. 8 Limits of Agreement for mean Peak Torque measurements-right 


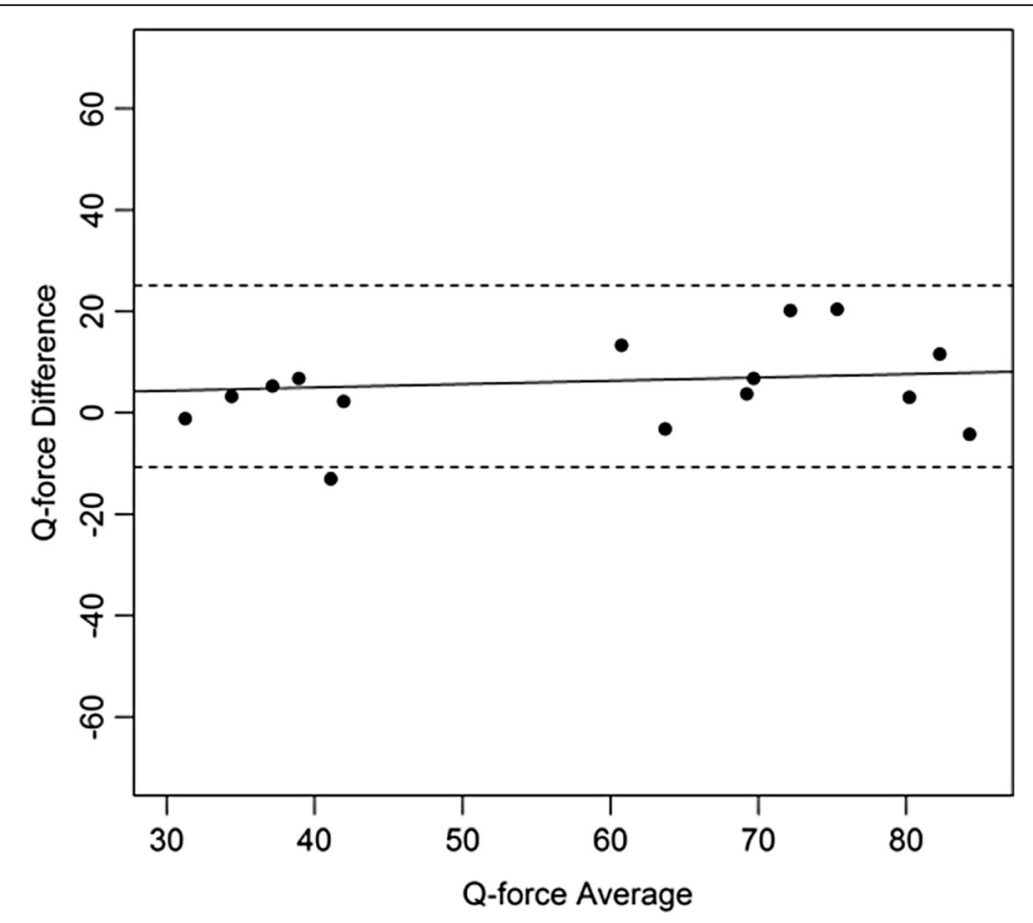

Fig. 9 Limits of Agreement for mean Median Peak Torque measurements-right

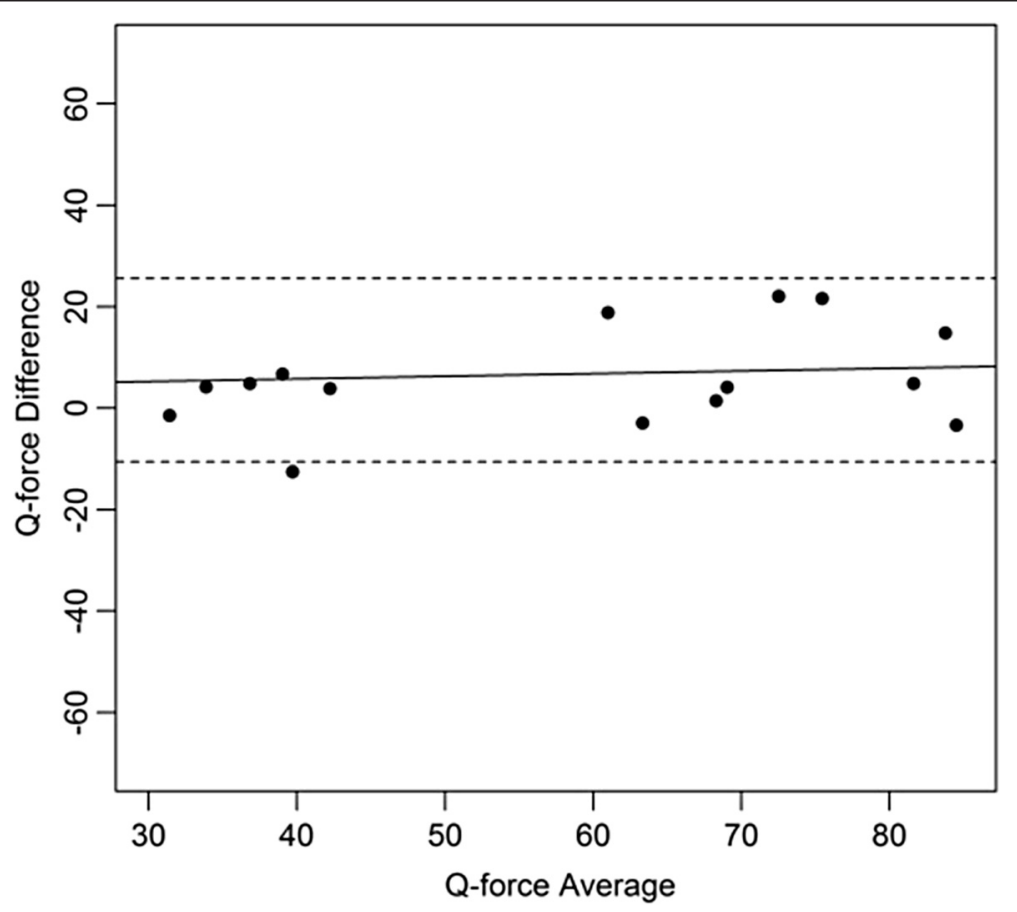

Fig. 10 Limits of Agreement for mean Plateau Peak Torque measurements-right 


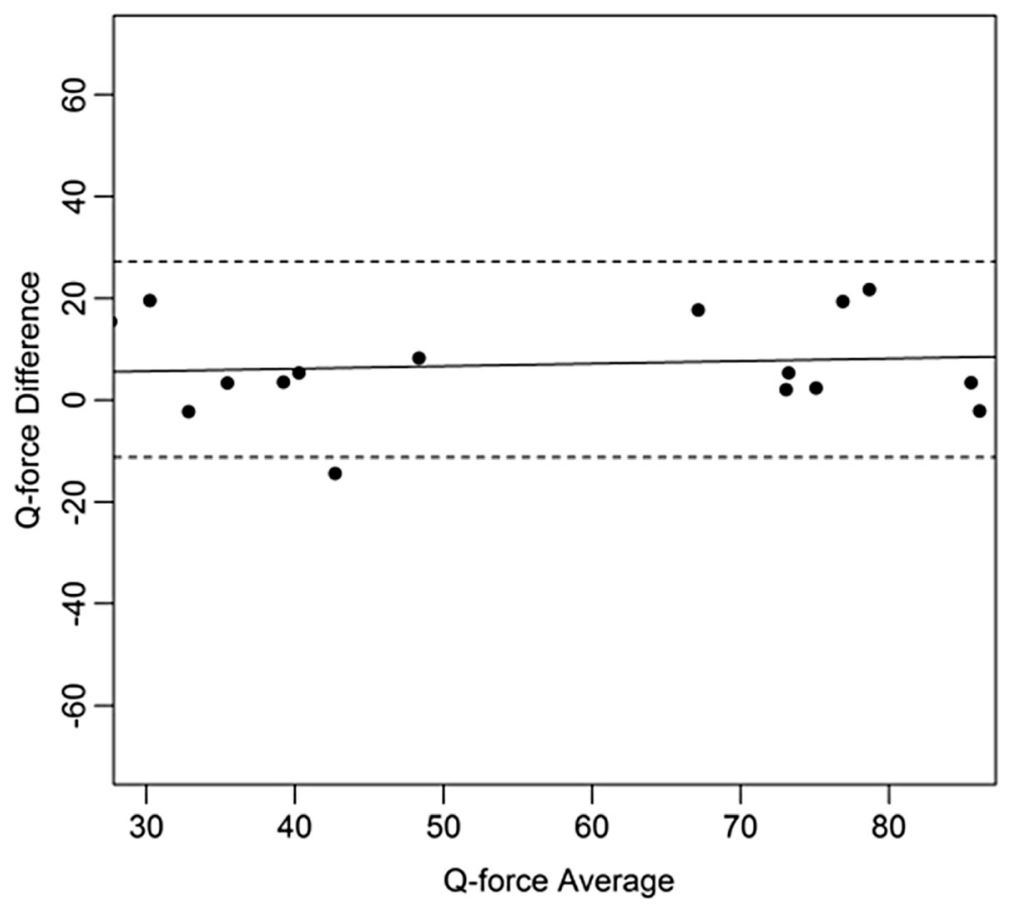

Fig. 11 Limits of agreement for mean Filtered Peak Torque measurements-right

ICC coefficients computed over the outcome measures, Peak 8Torque (PT), Filtered Peak Torque (FPT), Median peak Torque (MPT) and Average Plateau Peak Torque (APT) are very comparable, indicating that the relative reliability can be generalized over different types of muscle strength measures. We measured muscle strength at $110^{\circ}$ knee extension. Studies based on different degrees of extension ascertained ICC coefficients between 0.87 and 0.99 and are in accordance with our findings [20-23, 29, 37-41] This suggests that the reliability of Q Force measurements can be generalized to measurements other than $110^{\circ}$ extension.

ICC coefficients provide information regarding relative test-retest reliability of the instrument. The ICC coefficients do however not provide information on the magnitude of the intra individual variation between two observations [42]. These intra individual variations are represented by the absolute reliability as expressed by the limitis of agreement (LOA). The overall variation summarized in the LOA can be influenced by several sources of variation such as the time of the day, type of measurement, subject, observer, and protocol. The LOAs we found are substantial and vary between 15.7 and $23.6 \mathrm{Nm}$ which corresponds to $22.5 \%$ and $36 \%$ of the mean. This magnitude of the LOA's is consequential for clinical or research practice since a true change after training, for example, can only be detected if it is at least $22.5 \%$ in magnitude. Other studies with different type of instrumentation and different populations also describe a limited absolute reliability $[20,32,38,43$,
44]. This indicates that though the clinical usefulness of the Q Force for measuring muscle strength, the ability to detect changes over time is limited, although quite comparable with other instruments. In addition, the measurements outcomes for the right leg presents smaller LOA than the left. The different LOA size between the left and right leg can possibly be explained by differences in individual variation due to the fact that the majority of a population is right-side dominant [44]. Right dominance might result in a increased neural drive to the dominant right leg resulting in more consistent values. However differences in ICC and LOA values between left and right are not always found in comparable studies.

By the results of the paired T-test we found systematic differences between the first and second session in the sense that means on the second are approximately ten percent higher compared to the first session. Other studies using isokinetic devices or pre trials prior to the actual measurement also present systematic differences or a tendency to higher values at the second measurement session [45-50]. Several studies suggest that fear, a distinct learning effect or increased muscle recruitment may be responsible for systematic differences [20, 28, 46-50].

In our study we tested a population of healthy older adults. It does not provide any information about measurements reliably for example a chronically ill population or healthy working adults. We did not register if people were left or right dominant. This limits de insight in the origin of the observed difference in ICC, LOA 
between left and right. We did not perform pre trials at session 1 which might contribute to the observed differences between the measured values during session 1 and 2 . Though strength measurements reflect the quadriceps muscle force however no reliable procedures are available translating muscle strength into function. Therefore interpretation of strength measurement should be performed with caution.

Though muscle strength is often decreased in older subjects and associated with balance deficits and risk of falling, it is probably insufficient to use only muscle strength measurements in the predicting of fall incidents. A combination of measurements of muscle strength and functional rising and walking tests may increase the predictive capacity considerably.

\section{Conclusion}

Q Force measurements in $110^{\circ}$ extension have excellent absolute reliability (ICC), but only moderate absolute reliability (LOA). The size of the latter indicates a limited capability to detect changes in muscle force over time. Since the Q Force is relatively cheap and mobile it seems suitable for application in various clinical settings. Future studies should investigate the degree in which its discriminative ability can be improved especially in older adults.

\section{Abbreviations}

APT: average plateau peak torque; FPT: filtered peak torque; ICC: intraclass correlation coefficient; LOA: limits of agreement; MPT: median peak torque; MRC: medical research council scale; PT: peak torque.

\section{Competing interests}

The authors declare that they have no competing interests.

\section{Authors' contributions}

KWD Made substantial intellectual contributions the draft of the manuscript design and analysis and interpretation of the data and wrote the manuscript. GRHR Made substantial intellectual contributions the draft of the manuscript and to the conception and design and analysis and interpretation of the data. Contributed to the development of the $\mathrm{Q}$ force. Contributed to the development of the software and collected the original data. WPK Made substantial intellectual contributions the draft of the manuscript and design and analysis and interpretation of the data. Supervised the statistical analysis and interpretation. GECS Made substantial intellectual contributions the draft of the manuscript and interpretation of the data. CPS Made substantial intellectual contributions the draft of the manuscript design and analysis and interpretation of the data and supervised the development of the manuscript process. WZ Made substantial intellectual contributions the draft of the manuscript and to the conception and design and analysis and interpretation of the data. Contributed to original concept of the $Q$ force and further development of the $\mathrm{Q}$ force. Contributed to the development of the software and to the collection the original data. Authors give final approval of the version to be submitted and any revised version.

\section{Acknowledgements}

None

\section{Author details}

${ }^{1}$ Research and Innovation Group in Healthy Aging, Allied Health Care and Nursing, Hanze University of Applied Sciences Groningen, Groningen, The Netherlands. ${ }^{2}$ Department of Rehabilitation Medicine, University of Groningen, University Medical Center Groningen, Groningen, The Netherlands. ${ }^{3}$ University of Groningen, University Medical Center Groningen,
Center for Human Movement Sciences Groningen, Groningen, The Netherlands. ${ }^{4}$ School of Health Care Studies Hanze University of Applied Science Groningen, Groningen, The Netherlands. Institute of Movement and Sport Gerontology, German Sport University, Cologne, Germany.

Received: 23 June 2015 Accepted: 2 February 2016

Published online: 19 February 2016

\section{References}

1. Muehlbauer T, Besemer C, Wehrle A, Gollhofer A, Granacher A. Relationship between strength, power and balance performance in seniors. Gerontology. 2012;58:504-12.

2. Daubney ME, Culham GE. Lower-extremity muscle force and balance performance in adults aged 65 years and older. Phys Ther. 1999;79:1177-85.

3. Brooks SV, Faulkner JA. Skeletal muscle weakness in old age; underlying mechanisms. Med Sci Sports Exe. 1994;26:432-9.

4. Guralnik JM, Simonsick EM, Ferrucci L, Glynn RJ, Berkman LF, Blazer DG, et al. A short physical performance battery assessing lower extremity functio:association with self-reported disability and prediction of mortality and nursing home admission. J Geront. 1994;49:85-94.

5. Howe TE, Rochester L, Neil F, Skelton DA, Ballinger C. Exercise for improving balance in older people. Cochrane Database Syst Rev. 2011;11. doi:10.1002/ 14651858.

6. Ciciliot S, Rossi A, Dyar KA, Blaauw B, Schiaffino S. Muscle type and fiber type specificity in muscle wasting. Int J Biochem Cell Biol. 2013;45(10):2191-9.

7. Horlings CGC, van Engelen BGM, Allum JHJ, Bloem BR. A weak balance: the contribution of muscle weakness to postural instability and falls. Nat Rev Neurol. 2008:4:504-15.

8. Zasadzka E, Borowicz AM, Roszak M, Pawlaczyk M. Assessment of the risk of falling with the use of timed up and go test in the elderly with lower extremity osteoarthritis. Clin Interv Aging. 2015;10:1289-98.

9. YY Cheng YY, Wei SH, Chen PY, Tsai MW, Cheng IC. Can sit-to-stand lower limb muscle power predict fall status? Gait Posture. 2014;40(3):403-7.

10. Pijnappels M, Van der Burg JCE. Identification of elderly fallers by muscle strength measures. Eur J Appl Physiol. 2008;201:585-92.

11. Evans $D$, Pester J, Vera $L$, Jeanmonod D, Jeanmonod R. Elderly fall patients triaged to the trauma bay: age, injury patterns, and mortality risk. Am J Emerg Med. 2015;11(33):1635-8.

12. Beauchet O, Fantino B, Allali G, Muir SW, Montero-Odasso M, Annweiler C. Timed up and go test and risk of falls in older adults: a systematic review. J Nutr Health Aging. 2011;15(10):933-8.

13. de Souza Moreira B, Barroso CM, Cavalcanti Furtado CR, Ferreira Sampaio R, das Chagas Vallone MLD, Kirkwood RN. Clinical functional tests help identify elderly women highly concerned about falls. Exp Aging Res. 2015;41(1):89-103.

14. Andres PL, Skeny LM, Munsat TL. Measurement of strength in neuromuscular diseases. In: Munsat TL, editor. Quantification of neurologic deficit. Boston: Butterworths; 1989. p. 87-100.

15. Beasley WC. Influence of method on estimates of normal knee extensor force among normal and postpolio children. Phys Ther. 1956;36:21-41.

16. Van der Ploeg RJO, Oosterhuis HJGH, Reuvekamp J. Measuring muscle strength. J Neurol. 1984;231:200-3.

17. Schwartz S, Cohen ME, Herbison GJ, Shah A. Relationship between two measures of upper extremity strength: manual muscle test compared to hand-held myometry. Arch Phys Med Rehabil. 1992;73(11):1063-8.

18. MacAvoy MC, Green DP. Critical reappraisal of medical research council muscle testing for elbow flexion. J Hand Surg. 2007;32(2):149-53.

19. Dunn JC, Iversen MD. Interrater reliability of knee muscle forces obtained by hand-held dynamometer from elderly subjects with degenerative back pain. J Geriatr Phys Ther. 2003;26:23-9.

20. Wang CY, Olson SL, Protas EJ. Test-retest strength reliability: hand-held dynamometry in community dwelling elderly fallers. Arch Phys Med Rehabil. 2002;83:811-5.

21. Gilles Roy MA, Doherty TJ. Reliability of hand-held dynamometry in assessment of knee extensor strength after hip fracture. Am J Phys Med Rehab. 2004;83:813-8.

22. Bohannon RW, Andrews AW. Interrater reliability of hand-held dynamometry. Phys Ther. 1987;67:931-3.

23. Andrews AW, Thomas MW, Bohannon RW. Normative values for muscle strength obtained by hand-held dynamometry. Phys Ther. 1996;76:248-59.

24. Bohannon RW. Comparability of force measurements obtained with different strain gauge hand-held dynamometers. J Orthop Sports Phys Ther. 1993;18:564-7. 
25. Bohannon RW. Comparability of force measurements obtained with different hand-held dynamometers from older adults. Isokinet Exerc Sci. 1993;3:148-51.

26. Ullrich B, Brueggemann GP. Moment-knee angle relation inWell trained athletes. Int J Sports Med. 2008;29(8):639-45.

27. Sosnoff JJ, Voudrie SJ, Ebersole KT. The effect of knee joint angle on torque control, journal of motor behavior. J Mot Behav. 2009:42(1):5-10.

28. Narici MV, Hoppeler H, Kayser BL, Landoni H, Claassen C, Gavardi G, et al. Human quadriceps cross-sectional area, torque and neural activation during 6 months strength training. Acta Physiol Scand. 1996;157:175-86.

29. Phillips BA, Lo SK, Frank L, Mastaglia MD. Muscle force measured using "break" testing with a hand-held myometer in normal subjects aged 20 to 69 years. Arch Phys Med Rehabil. 2000;81(5):653-61.

30. Wikholm JB, Bohannon RW. Hand-held dynamometer measurements: tester strength makes a difference. J Orthop Sports Ther. 1991;13:191-8.

31. Verkerke GJ, Lemmink KAPM, Slagers AJ, Westhof MA, van Riet JA, Rakhorst G. Precision, comfort and mechanical performance of the Quadriso-tester, a quadriceps force measuring device. Med Biol Eng Comput. 2003:41:283-9.

32. Winter DA. Biomechanics of human movement. New York: Wiley; 1979.

33. Bland JM, Altman DG. Statistical methods for assessing agreement between two methods of clinical measuring. The Lancet. 1986;1 (8476):307-10.

34. McGraw KO, Wong SP. Forming inferences about some intraclass correlation coefficients. Psych Meth. 1996;1:30-46.

35. Shrout PE, Fleiss JL. Intraclass correlations: uses in assessing rater reliability. Psychol Bull. 1979;86:420-8

36. Fleiss JL. Chapter 1: reliability of measurement. The design and analysis of clinical experiments. London: Wiley; 1986. p. 1-33.

37. Janssen JC, Le-Ngoc L. Intratester reliability and validity of concentric measurements using a New hand-held dynamometer. Arch Phys Med Rehabil. 2009;90(9):1541-7.

38. Douma KW, Soer R, Krijnen WP, Reneman M, van der Schans CP. Reference values for isometric muscle force among workers for the Netherlands: a comparison of reference values. BMC Sports Sci Med Rehabil. 2014;6:10.

39. Buckinx F, Croisier JL, Reginster JY, Dardenne N, Beaudart C, Slomian J, et al. Reliability of muscle strength measures obtained with a hand-held dynamometer in an elderly population. Clin Physiol Funct Imaging. 2015;30: 10.1111

40. Cadogan A, Laslett M, Hing W, McNair P, Williams M. Reliability of a new hand-held dynamometer in measuring shoulder range of motion and strength. Manual Therapy. 2011;16:97-101.

41. Reuter SE, Massy-Westropp N, Evans AM. Reliability and validity of indices of hand-grip strength and endurance. Aust Occup Ther J. 2011;58:82-7.

42. Evans WJ, Cayten CG, Green PA. Determining the generalizability of rating scales in clinical settings. Med Care. 1981;14:1211-20.

43. Bardis C, Kalamara G, Loucaides G, Michaelides M, Tsaklis P. Intramachine and intermachine reproducibility of concentric performance: A study of the Con-Trex MJ and the Cybex Norm dynamometers. Isokinet Exerc Sci. 2004;12:91-7.

44. Porac S, Coren S. Lateral preferences and human behavior. New York: Springer; 1981.

45. O'Shea SD, Taylor NF, Paratz JD. Measuring muscle strength for people with chronic obstructive pulmonary disease: retest reliability of hand-held dynamometry. Arch Phys Med Rehabil. 2007;88(1):32-8.

46. Ritti-Dias RM, Basyches M, Câmara L, Puech-Leao P, Battistella L, Nelson Wolosker N. Test-retest reliability of isokinetic strength and endurance tests in patients with intermittent claudication. Vasc Med. 2010;15(4):275-8.

47. Barden HL, Nott MT, Baguley IJ, Heard R, Chapparo C. Test-retest reliability of computerized hand dynamometry in adults with acquired brain injury. Aust Occup Ther J. 2012;59:319-27.

48. Scott DA, Quin Bond E, Ann Sisto S, Nadler SF. The intra- and interrater reliability of Hip muscle strength assessments using a handheld versus a portable dynamometer anchoring station. Arch Phys Med Rehabil. 2004;85(4):598-603.

49. Almosnino S, Stevenson JM, Bardana DD, Diaconescu ED, Dvirb Z Reproducibility of isokinetic knee eccentric and concentric strength indices in asymptomatic young adults. Phys Ther Sport. 2012;13(3):156-62.

50. Wadsworth $C T$, Krishnan R, Sear M, Harrold J, Nielsen DH. Intrarater reliability of manual and hand held muscle testing. Phys Ther. 1987;67:1342-7.

\section{Submit your next manuscript to BioMed Central and we will help you at every step:}

- We accept pre-submission inquiries

- Our selector tool helps you to find the most relevant journal

- We provide round the clock customer support

- Convenient online submission

- Thorough peer review

- Inclusion in PubMed and all major indexing services

- Maximum visibility for your research

Submit your manuscript at www.biomedcentral.com/submit
Biomed Central 